\title{
Synthesis and Characterization of Colloidal CZTS Nanocrystals by a Hot-Injection Method
}

\author{
A. Méndez-López, ${ }^{1,2}$ A. Morales-Acevedo, ${ }^{1}$ Y. J. Acosta-Silva, ${ }^{3}$ and M. Ortega-López ${ }^{1}$ \\ ${ }^{1}$ Sección de Electrónica del Estado Solido (SEES), Departamento de Ingeniería Eléctrica, Centro de Investigación y \\ de Estudios Avanzados del Instituto Politécnico Nacional, Avenida IPN No. 2508, 07360 Mexico, DF, Mexico \\ ${ }^{2}$ División de Investigación y Posgrado, Facultad de Ingeniería, Universidad Autónoma de Querétaro, Querétaro, QRO, Mexico \\ ${ }^{3}$ Departamento de Física, Centro de Investigación y de Estudios Avanzados del Instituto Politécnico Nacional, \\ Avenida IPN No. 2508, 07360 Mexico, DF, Mexico \\ Correspondence should be addressed to A. Méndez-López; arturo.mendez@uaq.mx
}

Received 28 January 2015; Revised 2 June 2015; Accepted 11 November 2015

Academic Editor: Mohamed Bououdina

Copyright (C) 2016 A. Méndez-López et al. This is an open access article distributed under the Creative Commons Attribution License, which permits unrestricted use, distribution, and reproduction in any medium, provided the original work is properly cited.

\begin{abstract}
The present study reports the synthesis of colloidal $\mathrm{Cu}_{2} \mathrm{ZnSnS}_{4}$ (CZTS) nanocrystals (average size $\sim 4-9 \mathrm{~nm}$ ) by a simple and low cost hot-injection method. These nanocrystals form larger particles with sizes around $40 \mathrm{~nm}$. Oleylamine (OLA) was used as both the solvent and the nanocrystal stabilizer. The effect of the synthesis time on the structural, compositional, morphological, and optical properties was studied. As revealed by XRD, Raman, and TEM measurements all the prepared samples are comprised of both kesterite and wurtzite CZTS nanocrystals. The wurtzite phase contribution reduces as the reaction time is increased. The "bandgap" of the obtained nanoparticles tends to $1.52 \mathrm{eV}$ for the larger synthesis times $(24 \mathrm{~h})$ which is suitable for an absorber layer in thin films solar cells.
\end{abstract}

\section{Introduction}

The $\mathrm{Cu}_{2} \mathrm{ZnSnS}_{4}$ (CZTS) is a direct band gap semiconductor with high absorption coefficient in the visible region $\left(>10^{4} \mathrm{~cm}^{-1}\right)$ and an energy band gap in the $1.4-1.6 \mathrm{eV}$ range, which is very close to the optimum value for the absorber layer of thin film solar cells $[1,2]$. In the last years CZTS has intensively been studied as a promising cheap and green photovoltaic material, because it comprises earth abundant and nontoxic elements [3]. To date, CZTS thin films have been prepared by various experimental techniques such as atom beam sputtering [4], thermal evaporation of its constituents [5], spray pyrolysis [6], and sol-gel [7]. Recently, colloidal CZTS nanocrystals prepared by the hot-injection method have paid much attention in the solution processable solar cells technology, because its chemistry and viscosity can be tailored to be used as the raw material in the thin films deposition using ink-printing, spraying, dip-coating, or rollto-roll coating under ambient condition [8]. CZTS displays polymorphism with kesterite or stannite crystal structure. At the nanometer scale, CZTS also crystallizes in the kesterite or stannite phase, which resemble the tetragonal unitary cell $[9,10]$. Recently, however, several workers reported the synthesis of colloidal wurtzite CZTS by hot-injection method $[11,12]$. In this contribution, we present the synthesis and characterization of colloidal CZTS nanocrystals with the kesterite as the predominant phase. The nanocrystals are readily produced by using thioacetamide as the sulfur source in oleylamine. The structural and optical properties of colloidal nanocrystals formation have been systematically studied by X-ray diffraction, Raman spectroscopy, scanning electron microscopy (SEM), energy dispersive X-ray spectroscopy (EDS), transmission electron microscopy (TEM), and UV-Vis.

\section{Experimental}

2.1. Synthesis of CZTS Nanocrystals. Colloidal CZTS nanocrystals were synthesized by hot-injection using oleylamine as solvent and capping agent, following a procedure first 
reported by Joo et al. [13] with slight modifications. In a typical synthesis of CZTS nanocrystals, $2 \mathrm{mmol}$ of copper (II) chloride dihydrate $\left(\mathrm{CuCl}_{2}, 99 \%\right.$, Aldrich), $1 \mathrm{mmol}$ of zinc chloride ( $\mathrm{ZnCl}, 99 \%$, Aldrich), $1 \mathrm{mmol}$ of Tin (II) chloride dihydrate $\left(\mathrm{SnCl}_{2}, 98 \%\right.$, Aldrich), and $20 \mathrm{~mL}$ of oleylamine (OLA, 70\%, Fluka) were mixed in a $50 \mathrm{~mL}$ three-neck roundbottom flask, stirred and heated to $170^{\circ} \mathrm{C}$ for $1 \mathrm{~h}$ under inert atmosphere of argon (99.999\%). When the temperature reached $120^{\circ} \mathrm{C}$, the color of the mixture gradually changed from dark blue to a brown-yellow color. Meanwhile, another solution was prepared, for which $4 \mathrm{mmol}$ thioacetamide was dissolved in $3 \mathrm{~mL}$ oleylamine, under magnetic stirring, until the thioacetamide was dissolved and a green-yellow solution was obtained. Afterwards, brown-yellow solution was heated to $230^{\circ} \mathrm{C}$ and the thioacetamide-oleylamine solution was rapidly injected; then the temperature mixture solution was kept during different times, 3-24 hours. After the reaction had finished, the flask was removed from the heating mantle and allowed to naturally cool to room temperature; $5 \mathrm{~mL}$ of toluene was added to the flask. To washing or purifying the product, $40 \mathrm{~mL}$ of ethanol was firstly added and went through ultrasonic dispersion for $30 \mathrm{~min}$ and was then centrifuged at $4000 \mathrm{rpm}$ for $30 \mathrm{~min}$ to let the nanocrystals flocculate and precipitate to remove some unreacted chemicals and byproducts; its precipitate was redispersed by adding $40 \mathrm{~mL}$ of ethanol ultrasonically for $30 \mathrm{~min}$ and nanocrystals were again isolated by centrifugation at $4400 \mathrm{rpm}$ for $30 \mathrm{~min}$, with the purpose of letting the nanocrystals flocculate and precipitate to again remove some unreacted chemicals and byproducts. The above process was repeated for three times. The final precipitates (or CZTS nanocrystals) were dispersed in ethanol to form a stable ink solution with high purity. CZTS films were prepared on a soda-lime glass by dropcoating, drying at room temperature.

2.2. Characterization Methods. The crystallographic information of the nanocrystals was obtained from the powder X-ray diffraction patterns (PANalytical X'pert PRO X-ray diffractometer), using the $\mathrm{CuK} \alpha$ radiation with a wavelength of $1.5405 \AA$ in the range $20-70^{\circ}$. Raman spectroscopy was carried out using a Jobin Horiba model microspectrometer, with a He-Ne laser that emitted a wavelength of $632.8 \mathrm{~nm}$ and a power of $20 \mathrm{~mW}$. The Raman spectra samples were measured at room temperature in a wavelength range between 200 and $600 \mathrm{~nm}$, using a 50x objective to focalize the laser spot. All spectra were calibrated with respect to the silicon Raman mode at $520.7 \mathrm{~cm}^{-1}$. The morphology of CZTS nanocrystals was determined using an Auriga Zeiss 90-36 scanning electron microscope. Transmission electron microscopy study was obtained using a JEOL model 2010 transmission electron microscope, operating at $200 \mathrm{kV}$, with a point to point resolution of $0.18 \mathrm{~nm}$.

\section{Results and Discussion}

3.1. XRD Characterization. As above explained, CZTS nanocrystals were synthesized by a hot-injection method in

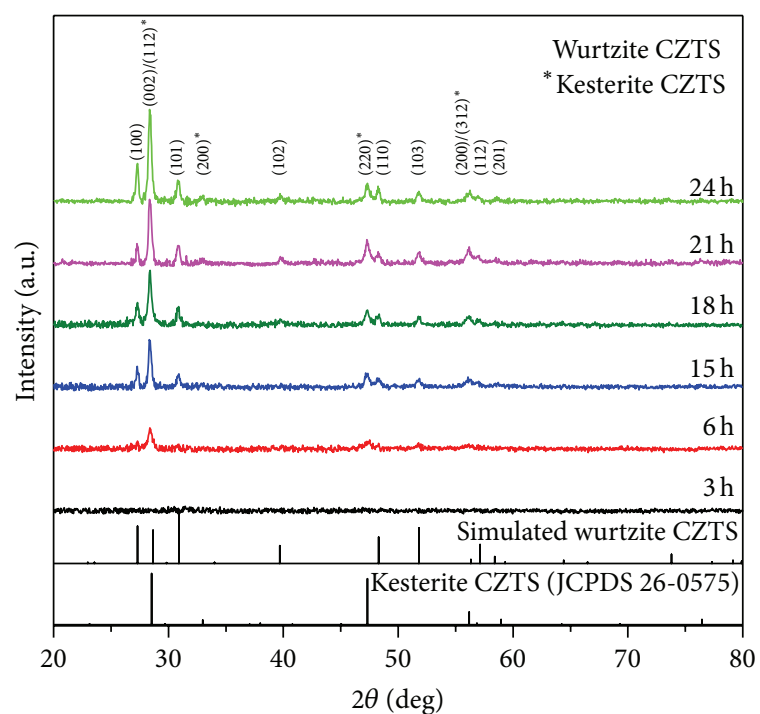

FIGURE 1: XRD patterns of CZTS nanocrystals obtained after reaction at $230^{\circ} \mathrm{C}$ for different times, that is, 3 hours, 6 hours, 15 hours, 18 hours, 21 hours, and 24 hours. Shown below are the patterns of the starting phase kesterite CZTS (JCPDS Card number 26-0575) and the simulated pattern of wurtzite CZTS.

which the thioacetamide precursor was poured into a hot solution at a given reaction temperature.

In order to gain insight on the nanocrystals formation process, we examined the nanocrystals synthesized at $230^{\circ} \mathrm{C}$ and the synthesis time was varied from $3 \mathrm{~h}$ to $24 \mathrm{~h}$.

Figure 1 shows the XRD patterns of the CZTS nanocrystals synthesized. The XRD pattern of CZTS nanocrystals synthesized at 3 hours displays no discernible peaks, indicating a sample containing amorphous or very small particles. For reaction times of $6 \mathrm{~h}$ and longer, a series of the XRD peaks were observed. All well crystallized samples appear to consist of nanocrystals in which the kesterite and wurtzite phases coexist. The wurtzite planes were indexed according to simulated wurtzite patterns All the diffraction peaks appearing at $2 \theta=27.282^{\circ}, 28.365^{\circ}, 30.829^{\circ}, 39.829^{\circ}, 48.244^{\circ}$, $51.792^{\circ}, 56.161^{\circ}, 56.908^{\circ}$, and $58.639^{\circ}$ can be attributed to the (100), (002), (101), (102), (110), (103), (200), (112), and (201) planes of the wurtzite structure of CZTS [14]. There are some additional diffraction peaks at $2 \theta=28.365^{\circ}, 32.983^{\circ}$, $47.248^{\circ}$, and $56.161^{\circ}$. These peaks can be attributed to the (112), (200), (220), and (312) planes of the kesterite structure of CZTS. There is great similarity in the position of some peaks in the two crystal structures (wurtzite and kesterite). The weak diffraction peak at around $33^{\circ}$, which corresponds to the (200) plane of kesterite CZTS, can be used to track the kesterite crystal phase during the formation of the CZTS nanocrystals in the samples. Notice that the positions of the peaks associated with the (002) plane of the wurtzite coincide with the (112) peak associated with the kesterite structure. In addition, the diffraction due to the (200) planes of wurtzite coincides with the (312) planes for the kesterite phase. Then, we can conclude that there is a mixture of both kesterite and wurtzite phases of the CZTS nanocrystals in the films, but 
we cannot determine the relative fractions for each phase in our samples. The lattice parameters determined from the observed (002) and (101) spacing of the crystallites with the wurtzite structure were $a=3.7637 \AA$ and $c=6.2259 \AA$, in good agreement with the reported single crystal data of $a=$ $3.81 \AA$ and $c=6.28 \AA[15]$. For the crystallites with the kesterite structure, the lattice parameters are $a=5.43 \AA$ and $c=10.92 \AA$, as determined from the spacing of the (200) and (112) planes which are very similar to those reported for kesterite CZTS powders (JCPDS 26-0575).

The average size of the nanoparticles can be estimated from the XRD data using Scherrer's equation [16]:

$$
D=\frac{K \cdot \lambda}{\beta \cdot \cos \theta},
$$

where $D$ represents the crystallite size (nm), $\lambda=1.5406 \AA$ is the X-ray wavelength (for $\mathrm{CuK} \alpha$ line), $\beta$ is the peak width at half-maximum (FWHM, units in radians), $\theta$ is the angle of reflection, and $K=0.9$ is the shape factor. In accordance with the above, we can observe that the CZTS particle sizes increase for longer reaction times during the synthesis. The particle sizes on these films were estimated to be $\sim 20$ to $\sim 40 \mathrm{~nm}$.

3.2. Raman Spectroscopy Analysis. We used Raman spectroscopy to verify that all samples were pure CZTS without secondary phases. Indeed, Raman spectroscopy is a valuable tool to clearly identify CZTS and the binary $\left(\mathrm{ZnS}, \mathrm{Cu}_{2-x} \mathrm{~S}\right.$, $\left.\mathrm{SnS}_{2}\right)$ or ternary $\left(\mathrm{Cu}_{3} \mathrm{SnS}_{4}\right)$ chalcogenides which could originate during the CZTS synthesis. The main Raman peak for these chalcogenides comes out at $351 \mathrm{~cm}^{-1}(\mathrm{ZnS}), 475 \mathrm{~cm}^{-1}$ $\left(\mathrm{Cu}_{2-x} \mathrm{~S}\right), 315 \mathrm{~cm}^{-1}\left(\mathrm{SnS}_{2}\right)$, and $348 \mathrm{~cm}^{-1}\left(\mathrm{Cu}_{3} \mathrm{SnS}_{4}\right)$. Kesterite CZTS, on the other hand, displays Raman peaks at 252, 287, 339,351 , and $368 \mathrm{~cm}^{-1}$, with the highest intensity at $339 \mathrm{~cm}^{-1}$ [17]. Raman peaks for the wurtzite type structure of CZTS are reported in the range 331-338 [18].

Figure 2 shows the Raman spectra of the CTZS samples prepared at different reaction times. The Raman peak at $339 \mathrm{~cm}^{-1}$ (ascribed to vibrational Al mode of kesterite CZTS) suggests that the kesterite phase predominates in our CZTS samples. This Raman peak shifted to lower wave numbers, particularly for short synthesis times, implies that the wurtzite phase is present, but it diminishes as the deposition time is increased. The Raman spectra for the samples synthesized during large times ( 24 hours) are more typical of kesterite CZTS, but the peaks are broader with respect to those already reported, probably due to the small particle size effects. However, notice that the short range order of the CZTS nanocrystals forming the nanoparticles increases as the deposition time is increased. For the nanocrystals synthesized during 3 hours, the Raman peak intensity is very low, indicating that the CZTS particle size is very small, which is consistent with the XRD results.

3.3. Scanning Electron Microscopy (SEM). The chemical composition of our samples was assessed by scanning electron microscopy-energy-dispersive X-ray spectroscopy (SEMEDX). For simplicity, only the metals (Cu, $\mathrm{Zn}$, and $\mathrm{Sn}$ ) were

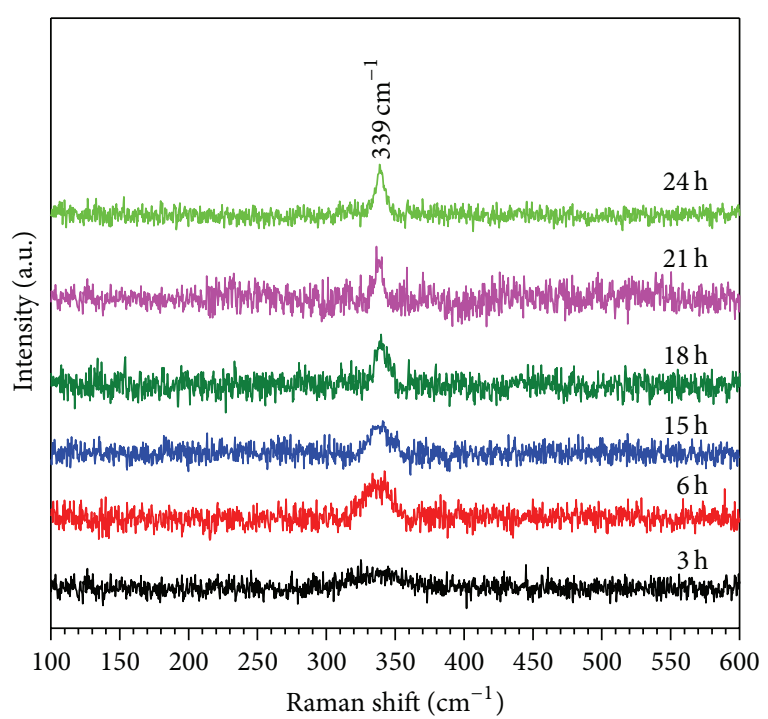

FIgURE 2: Raman spectra of CZTS nanocrystals obtained at $230^{\circ} \mathrm{C}$ during different reaction times.

TABLE 1: Chemical composition ratios of all samples measured in this study by EDX.

\begin{tabular}{lcc}
\hline \multirow{2}{*}{ Sample } & \multicolumn{2}{c}{ Chemical composition ratios } \\
& $\mathrm{Cu} /(\mathrm{Zn}+\mathrm{Sn})$ & $\mathrm{Zn} / \mathrm{Sn}$ \\
\hline CZTS, 3 h & 1.16 & 0.56 \\
CZTS, 6 h & 1.10 & 0.69 \\
CZTS, 15 h & 1.06 & 0.83 \\
CZTS, 18 h & 1.02 & 0.93 \\
CZTS, 21 h & 1.02 & 0.97 \\
CZTS, 24h & 1.01 & 0.98 \\
\hline
\end{tabular}

considered. This restriction is reasonable because there is always an excess of sulphur ( $\mathrm{S}$ ) during preparation, and it introduces only a small error in the film composition because the $\mathrm{S}$ contents were always close to $50 \%$. The stoichiometric composition of CZTS should be $2: 1: 1: 4$. We can see clearly in Table 1 that as the synthesis time is increased we are having a composition which tends more to this CZTS stoichiometry. Short synthesis times cause low zinc content in the samples. Zaberca et al. obtained a similar result using isopropanol as the solvent by a polycondensation reaction at $200^{\circ} \mathrm{C}$ [19]. Woo et al. reported results obtained with $\mathrm{Cu}$-poor and $\mathrm{Zn}$ rich compositions [17], and Chen et al. mentioned that for improved efficiency of solar cells CZTS must have a Cu-poor and $\mathrm{Zn}$-rich composition, as the $\mathrm{Zn}$ atoms in excess enter into the $\mathrm{Cu}$ vacancies [20]. Our synthesis process for 15 hours meets these characteristics. The results for 18, 21, and 24 hours are very similar, with compositions which are close to the volumetric CZTS stoichiometry.

Figure 3 shows the surface SEM image of $\mathrm{Cu}_{2} \mathrm{ZnSnS}_{4}$ nanocrystals dip-coated onto the SLG substrate. In Figure 3(a), it can be seen that reaction times of $3 \mathrm{~h}$ cause smoother surfaces and compact films than for larger times. 

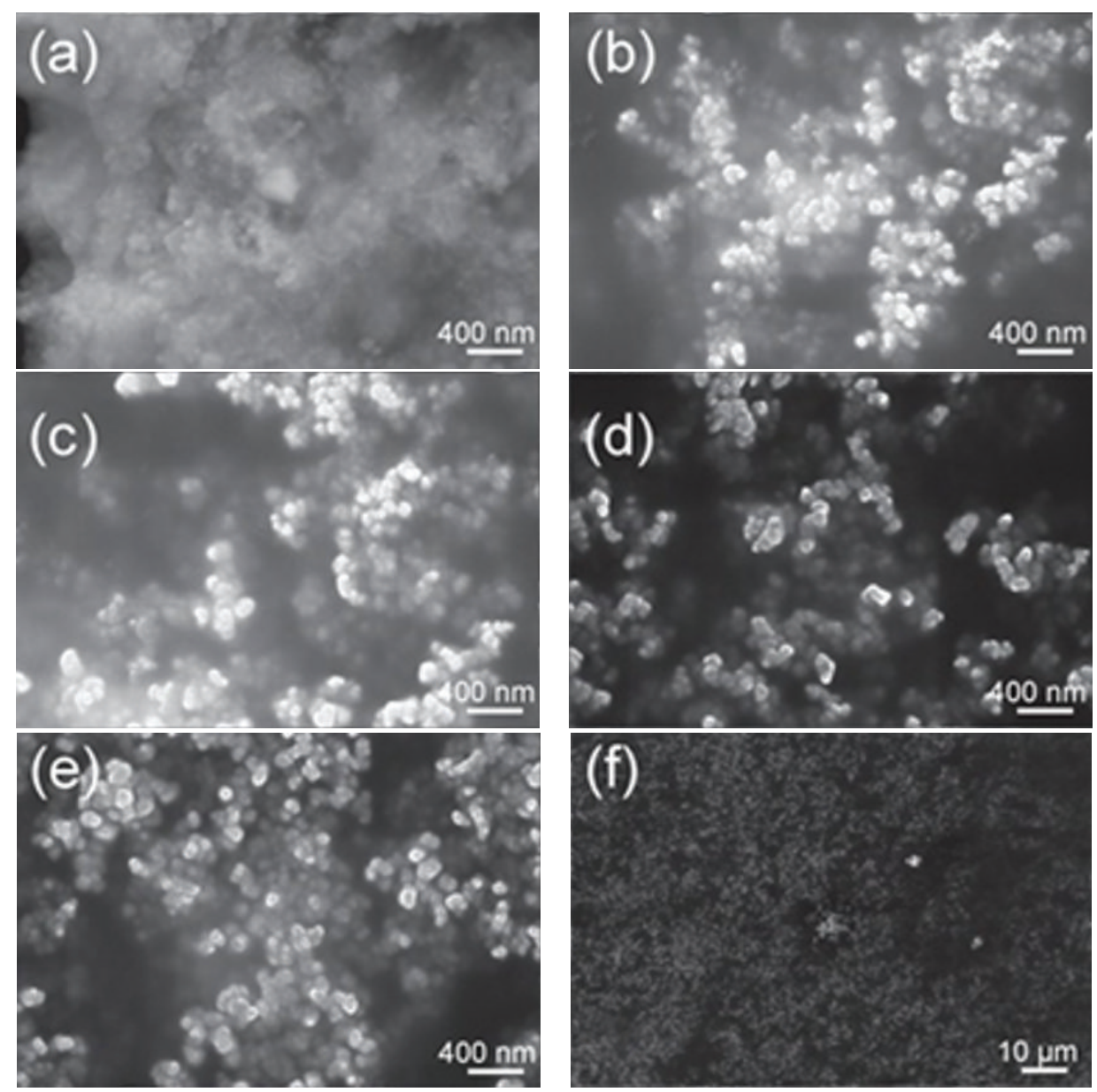

FIGURE 3: SEM of CZTS nanocrystals deposited on SLG substrates synthesized with different reaction times: $3 \mathrm{~h}$ (a), $6 \mathrm{~h}$ (b), $15 \mathrm{~h}$ (c), $18 \mathrm{~h} \mathrm{(d),}$ $21 \mathrm{~h}(\mathrm{e})$, and $24 \mathrm{~h}(\mathrm{f})$.

Previous works report similar result with $\mathrm{Cu}$-poor/Zn-rich composition [21].

For low synthesis times the SEM images show that the clusters were nonuniformly distributed over the substrate surface. However, the surface morphology of the $24 \mathrm{~h}$ sample (Figure 3(f)) shows that this sample has a uniform granular morphology with good homogeneity during the nanoparticle growth.

3.4. Transmission Electron Microscopy (TEM). A representative transmission electron microscopy (TEM) image of the CZTS nanocrystals produced for 24 hours is shown in Figure 4(a). The CZTS nanocrystals are slightly irregular and polydisperse. Homogeneous size control is still not available by this method for such complex quaternary materials. A high-resolution TEM image of a few selected particles (Figure 4(b)) shows that the CZTS nanocrystals produce clear lattice fringes. The fringes are regular with spacings $d$ $=0.33 \mathrm{~nm}$ and $d=0.31 \mathrm{~nm}$, which corresponds to the (100) lattice plane, and to the (002) lattice plane of wurtzite CZTS nanocrystals, respectively. In the inset of Figure 4(c), we plot a distribution of particle sizes as extracted from the TEM image. The sizes of the nanocrystals are found in the range from $4 \mathrm{~nm}$ to $9 \mathrm{~nm}$. We find that these values are not the same as determined from the XRD data because XRD peaks are associated with clusters (nanoparticles) formed by the CZTS nanocrystals. From the selected area electron diffraction (SAED) pattern, tetragonal symmetry was confirmed. The spots in the SAED pattern could very well be indexed to the planes observed by XRD (Figure 4(d)). Furthermore, the lattice spacing observed in these HR-TEM images of $3.3 \AA$ and $3.1 \AA$ corresponds to the (100) and (002)/(112) planes of CZTS, respectively. Then we confirm the tetragonal symmetry for the prepared CZTS nanocrystals (Figure 4(c)).

3.5. UV-Vis Absorption Spectra. The semiconducting band gap has been estimated based on its optical absorption properties investigated by UV-Vis absorption spectroscopy. As being a direct band gap semiconductor of CZTS, its band gap can be obtained from the $(\alpha E)^{2}$ versus $E$, where $E=$ $h \nu$ is the quantum energy of incident photons, and $\alpha$ is the absorption coefficient (Abs). The absorption curve and the derived curve of $(\alpha E)^{2}$ versus $E$ are shown in Figure 5(a) for 

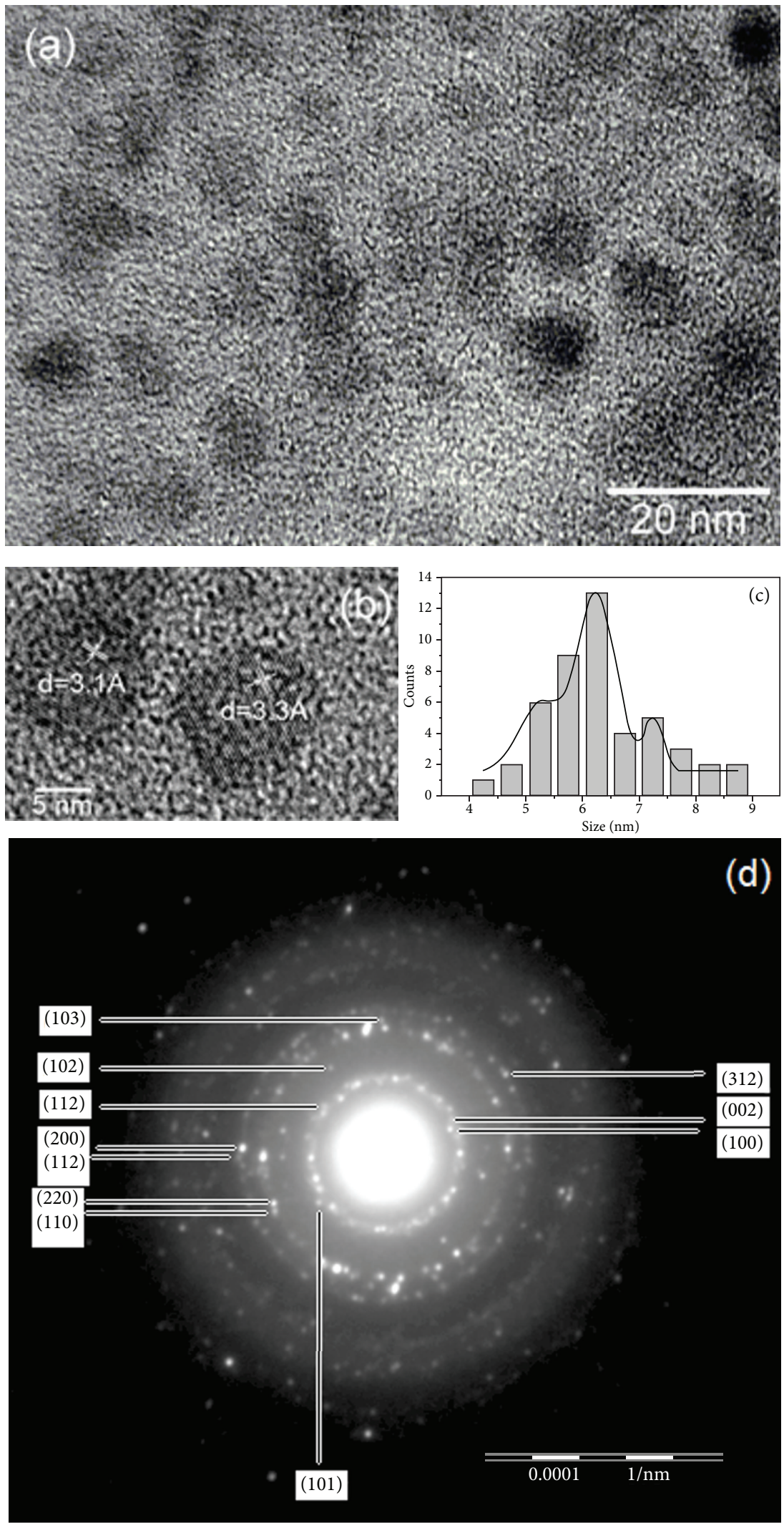

FIgURE 4: (a) A general overview TEM image of CZTS nanocrystals, (b) interplanar spacing of the (100) and (002) planes, (c) CZTS nanocrystals showing a wide size distribution varying from $4 \mathrm{~nm}$ to $9 \mathrm{~nm}$ with an average size of $6.25 \mathrm{~nm}$, and (d) selected area electron diffraction (SAED) pattern showing the presence of both kesterite and wurtzite crystalline phases. 


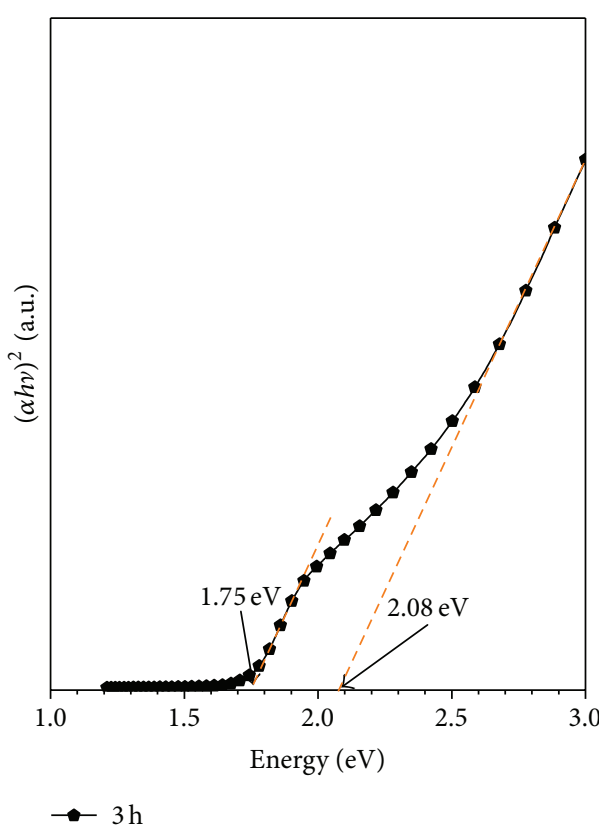

(a)

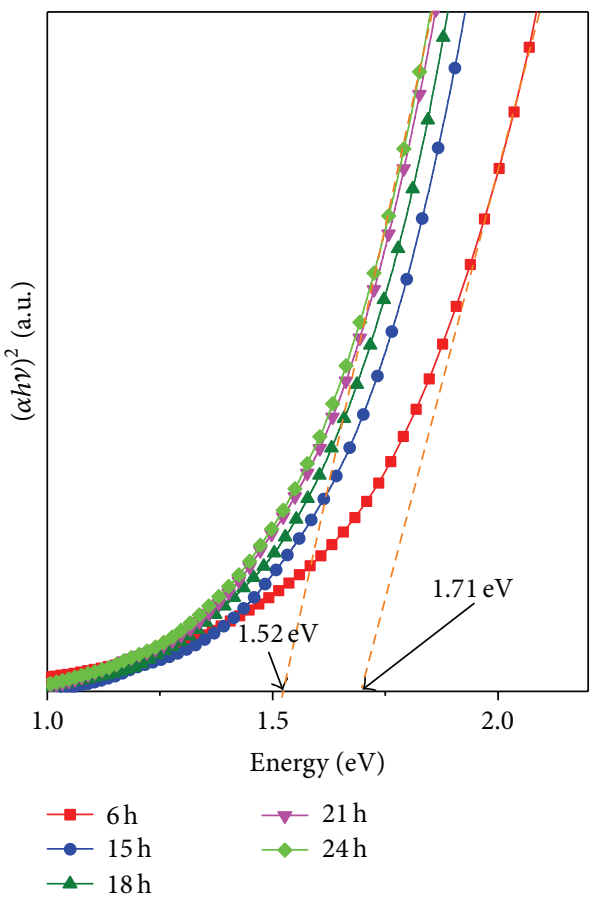

(b)

Figure 5: $(\alpha h \nu)^{2}$ versus $h \nu$ curve of CZTS thin films samples, (a) $3 \mathrm{~h}$ and (b) 6, 15, 18, 21, and $24 \mathrm{~h}$.

the sample synthetized during 3 hours and in Figure 5(b) for the other samples at longer times.

The band gap is determined from the Tauc plots [22]:

$$
(\alpha h v)^{2}=\beta\left(h v-E_{g}\right)
$$

where $\beta$ is a constant, $v$ is incident photon frequency, $h$ is Planck's constant, and $E_{g}$ is the band gap energy. The band gap energy is obtained by extrapolating the tangent line of the curve to the $x$-axis. The linear nature of the graphs supports the direct band gap nature of the semiconductor. The obtained $E_{g}$ values are 1.75, 1.71, 1.61, 1.59, 1.56, and $1.52 \mathrm{eV}$, respectively, which is in good agreement with CZTS band gap values reported by other authors [23-26]. As can be seen from Figure 5(a), for the $3 \mathrm{~h}$ samples two absorbing edges appear indicating two band gaps of $1.75 \mathrm{eV}$ and $2.08 \mathrm{eV}$, respectively, as shown in the inset. This indicates that there is not a single phase for these films. The possible secondary phases cannot be detected from either XRD or Raman spectra, due to its possible amorphous character and small particle sizes observed for the 3 hours samples. For larger synthesis times the observed results tend to the optical band gap of $1.52 \mathrm{eV}$, which is suitable for an absorber layer in thin films solar cells (Figure 5(b)).

\section{Conclusions}

In this contribution, we have shown that the quaternary semiconductor compound CZTS can be synthesized by a hotinjection method at constant temperature for 3-24 hours.
The obtained nanoparticles are formed by a mixture of both kesterite and wurtzite nanocrystals. The structures were studied by TEM, energy dispersive X-ray spectroscopy, and XRD. The factors that influence the formation of the CZTS nanocrystals were investigated. We found that, for long reaction times, the zinc atoms become embedded in the compound for the formation of CZTS nanocrystals with a thermodynamically metastable kesterite/wurtzite mixture. The XRD profile reveals the formation of this CZTS crystalline phase mixture with a decreasing amount of the wurtzite phase as the synthesis time is increased. This fact was confirmed by Raman spectroscopy and TEM electron diffraction patterns. In addition, EDX-analysis of the samples showed that the chemical composition of the CZTS nanocrystals is near the stoichiometric value. The prepared nanocrystals exhibit diameters between 4 and $9 \mathrm{~nm}$. This synthesized nanoparticles size estimated by XRD (Scherrer formula) is around $20-40 \mathrm{~nm}$. The nanoparticles are formed by nanocrystallites with sizes around $4-9 \mathrm{~nm}$ as determined from TEM measurements. The "band gap" of the obtained particles tends to $1.52 \mathrm{eV}$ for the larger synthesis times $(24 \mathrm{~h})$ which is suitable for an absorber layer in thin films solar cells. Our work provides a surfactant-free and solventredispersible hot-injection nanocrystal fabrication process which is simple, of low cost, and nontoxic.

\section{Conflict of Interests}

The authors declare that there is no conflict of interests regarding the publication of this paper. 


\section{Acknowledgments}

A. Méndez-López thanks Mr. Alvaro Guzman for the synthesis of nanoparticles and also M. C. Adolfo Tavira (XRD) and M. C. Miguel Galvan (Raman Spectroscopy) for their technical assistance. A. Méndez-López gratefully thanks Doctors Yasuhiro Matsumoto and Genaro Martin Soto-Zarazua and Professor Hironori Katagiri for their help which improved this work significantly.

\section{References}

[1] Q. Guo, S. J. Kim, M. Kar et al., "Development of CulnSe nanocrystal and nanoring inks for low-cost solar cells," Nano Letters, vol. 8, no. 9, pp. 2982-2987, 2008.

[2] C. Steinhagen, M. G. Panthani, V. Akhavan, B. Goodfellow, B. Koo, and B. A. Korgel, "Synthesis of $\mathrm{Cu}_{2} \mathrm{ZnSnS}_{4}$ nanocrystals for use in low-cost photovoltaics," Journal of the American Chemical Society, vol. 131, no. 35, pp. 12554-12555, 2009.

[3] W. Wang, M. T. Winkler, O. Gunawan et al., "Device characteristics of CZTSSe thin-film solar cells with $12.6 \%$ efficiency," Advanced Energy Materials, vol. 4, no. 7, Article ID 1301465, 2014.

[4] H. Yoo and J. Kim, "Growth of $\mathrm{Cu}_{2} \mathrm{Zn}_{S} \mathrm{nS}_{4}$ thin films using sulfurization of stacked metallic films," Thin Solid Films, vol. 518, no. 22, pp. 6567-6572, 2010.

[5] N. Nakayama and K. Ito, "Sprayed films of stannite $\mathrm{Cu}_{2} \mathrm{ZnSnS}_{4}$," Applied Surface Science, vol. 92, pp. 171-175, 1996.

[6] W. Daranfed, M. S. Aida, N. Attaf, J. Bougdira, and H. Rinnert, " $\mathrm{Cu}_{2} \mathrm{ZnSnS}_{4}$ thin films deposition by ultrasonic spray pyrolysis," Journal of Alloys and Compounds, vol. 542, pp. 22-27, 2012.

[7] M. Y. Yeh, C. C. Lee, and D. S. Wuu, "Influences of synthesizing temperatures on the properties of $\mathrm{Cu}_{2} \mathrm{ZnSnS}_{4}$ prepared by sol-gel spin-coated deposition," Journal of Sol-Gel Science and Technology, vol. 52, no. 1, pp. 65-68, 2009.

[8] M. Zhou, Y. Gong, J. Xu, G. Fang, Q. Xu, and J. Dong, "Colloidal CZTS nanoparticles and films: preparation and characterization," Journal of Alloys and Compounds, vol. 574, pp. 272-277, 2013.

[9] S. C. Riha, B. A. Parkinson, and A. L. Prieto, "Solution-based synthesis and characterization of $\mathrm{Cu}_{2} \mathrm{ZnSnS}_{4}$ nanocrystals," Journal of the American Chemical Society, vol. 131, no. 34, pp. 12054-12055, 2009.

[10] T. Kameyama, T. Osaki, K.-I. Okazaki et al., "Preparation and photoelectrochemical properties of densely immobilized $\mathrm{Cu}_{2} \mathrm{ZnSnS}_{4}$ nanoparticle films," Journal of Materials Chemistry, vol. 20, no. 25, pp. 5319-5324, 2010.

[11] X. T. Lu, Z. Zhuang, Q. Peng, and Y. Li, "Wurtzite $\mathrm{Cu}_{2} \mathrm{ZnSnS}_{4}$ nanocrystals: a novel quaternary semiconductor," Chemical Communications, vol. 47, no. 11, pp. 3141-3143, 2011.

[12] A. Singh, H. Geaney, F. Laffir, and K. M. Ryan, "Colloidal synthesis of wurtzite $\mathrm{Cu}_{2} \mathrm{ZnSnS}_{4}$ nanorods and their perpendicular assembly," Journal of the American Chemical Society, vol. 134, no. 6, pp. 2910-2913, 2012.

[13] J. Joo, H. B. Na, T. Yu et al., "Generalized and facile synthesis of semiconducting metal sulfide nanocrystals," Journal of the American Chemical Society, vol. 125, no. 36, pp. 11100-11105, 2003.

[14] J. Tao, J. Liu, J. He et al., "Synthesis and characterization of $\mathrm{Cu}_{2} \mathrm{ZnSnS}_{4}$ thin films by the sulfurization of co-electrodeposited $\mathrm{Cu}-\mathrm{Zn}$-Sn-S precursor layers for solar cell applications," RSC Advances, vol. 4, no. 46, pp. 23977-23984, 2014.
[15] M. Jao, H. Liao, M. Wu, and W. Su, "Synthesis and characterization of wurtzite $\mathrm{Cu}_{2} \mathrm{ZnSnS}_{4}$ nanocrystals," Japanese Journal of Applied Physics, vol. 51, no. 10, Article ID 10NC30, 2012.

[16] A. Méndez-López, A. Morales-Acevedo, Y. de Jesús Acosta-Silva et al., "Study of the synthesis of self- assembled tin disulfide nanoparticles prepared by a low-cost process," Physica Status Solidi (C), vol. 12, no. 6, pp. 564-567, 2015.

[17] K. Woo, Y. Kim, and J. Moon, "A non-toxic, solution-processed, earth abundant absorbing layer for thin-film solar cells," Energy \& Environmental Science, vol. 5, no. 1, pp. 5340-5345, 2012.

[18] Y. Zhao, Q. Qiao, W. Zhou et al., "Wurtzite $\mathrm{Cu}_{2} \mathrm{ZnSnS}_{4}$ nanospindles with enhanced optical and electrical properties," Chemical Physics Letters, vol. 592, pp. 144-148, 2014.

[19] O. Zaberca, A. Gillorin, B. Durand, and J. Y. Chane-Ching, "A general route to the synthesis of surfactant-free, solventdispersible ternary and quaternary chalcogenide nanocrystals," Journal of Materials Chemistry, vol. 21, no. 18, pp. 6483-6486, 2011.

[20] C. Zou, L. Zhang, D. Lin et al., "Facile synthesis of $\mathrm{Cu}_{2} \mathrm{ZnSnS}_{4}$ nanocrystals," CrystEngComm, vol. 13, no. 10, pp. 3310-3313, 2011.

[21] P. A. Fernandes, P. M. P. Salomé, and A. F. da Cunha, "Growth and Raman scattering characterization of $\mathrm{Cu}_{2} \mathrm{ZnSnS}_{4}$ thin films," Thin Solid Films, vol. 517, no. 7, pp. 2519-2523, 2009.

[22] A. Wei, Z. Yan, Y. Zhao, M. Zhuang, and J. Liu, "Solvothermal synthesis of $\mathrm{Cu}_{2} \mathrm{ZnSnS}_{4}$ nanocrystalline thin films for application of solar cells," International Journal of Hydrogen Energy, vol. 40, no. 1, pp. 797-805, 2015.

[23] F. Liu, Y. Li, K. Zhang et al., "In situ growth of $\mathrm{Cu}_{2} \mathrm{ZnSnS}_{4}$ thin films by reactive magnetron co-sputtering," Solar Energy Materials and Solar Cells, vol. 94, no. 12, pp. 2431-2434, 2010.

[24] A. Emrani, P. Vasekar, and C. R. Westgate, "Effects of sulfurization temperature on CZTS thin film solar cell performances," Solar Energy, vol. 98, pp. 335-340, 2013.

[25] L. Sun, J. He, H. Kong, F. Yue, P. Yang, and J. Chu, "Structure, composition and optical properties of $\mathrm{Cu}_{2} \mathrm{ZnSnS}_{4}$ thin films deposited by pulsed laser deposition method," Solar Energy Materials and Solar Cells, vol. 95, no. 10, pp. 2907-2913, 2011.

[26] S. Kahraman, S. Cetinkaya, H. A. Cetinkara, and H. S. Guder, "Effects of diethanolamine on sol-gel-processed $\mathrm{Cu}_{2} \mathrm{ZnSnS}_{4}$ photovoltaic absorber thin films," Materials Research Bulletin, vol. 50, pp. 165-171, 2014. 

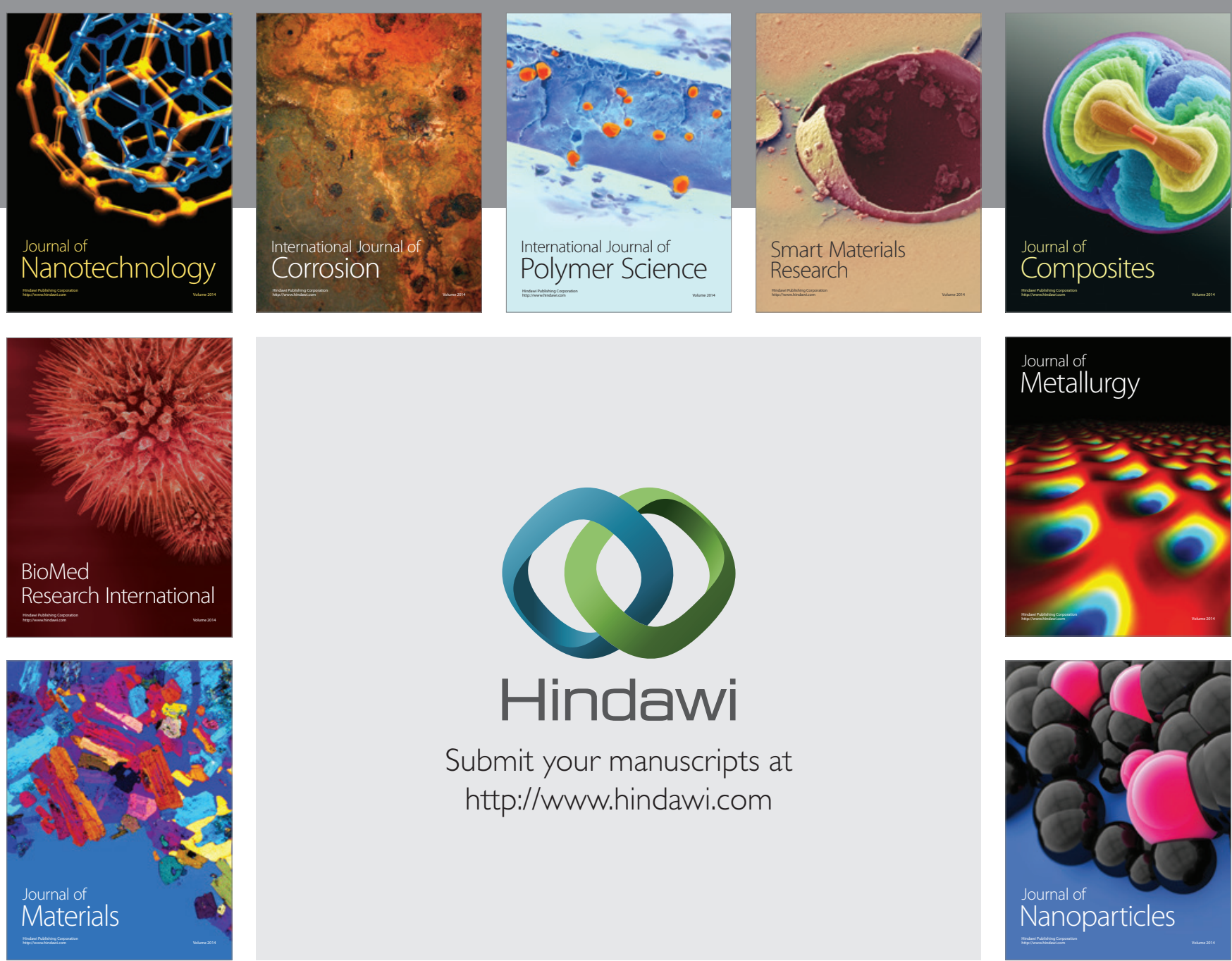

\section{Hindawi}

Submit your manuscripts at

http://www.hindawi.com

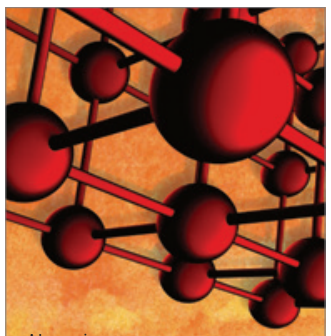

Materials Science and Engineering
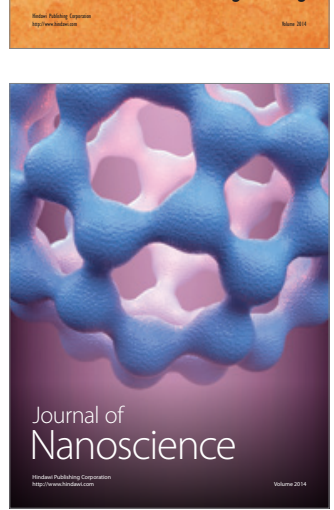
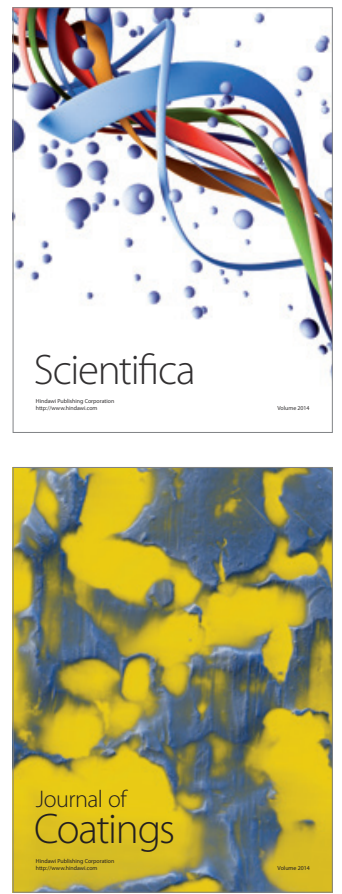
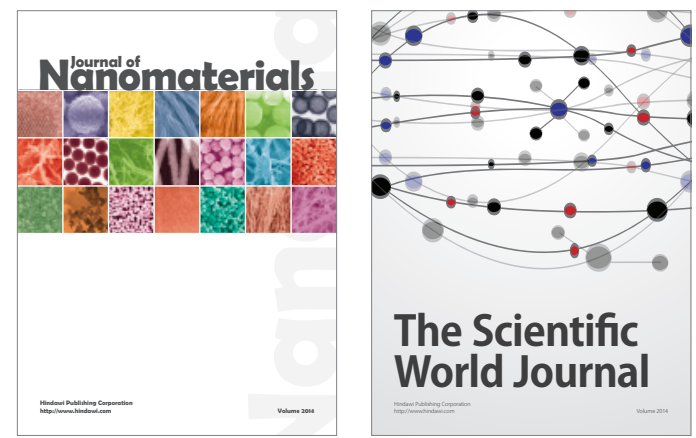

The Scientific World Journal
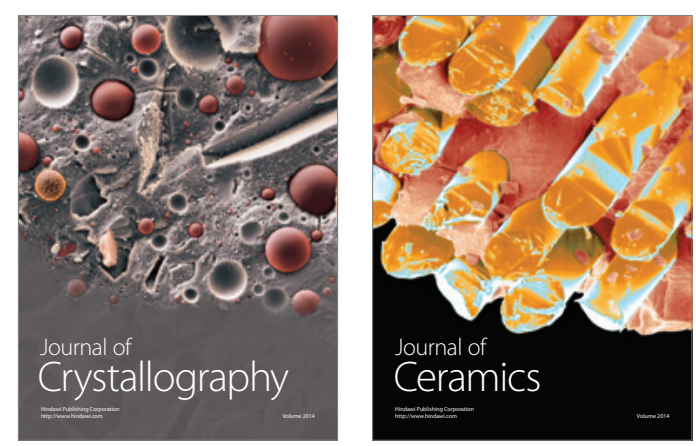
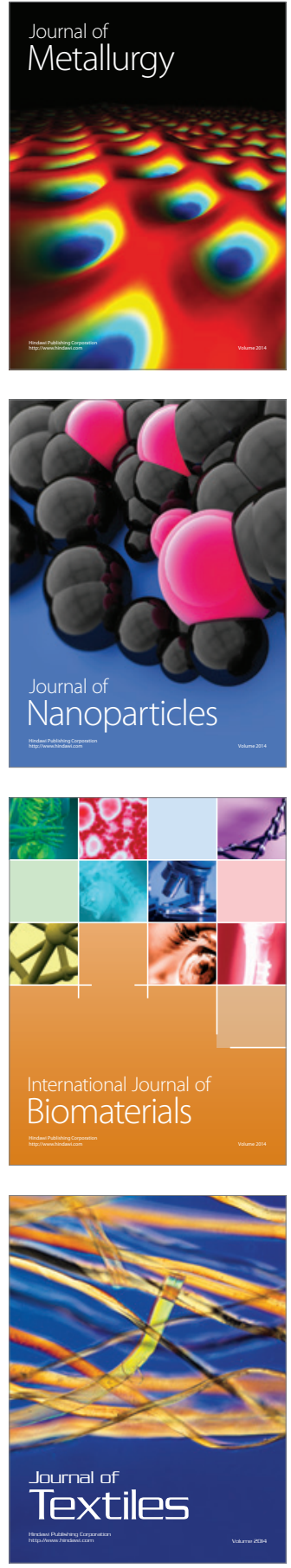